\title{
Electropolymerization of Nitrophenol Isomers in Various Aqueous Electrolytic Solutions
}

\author{
Ahmad S. Barham* \\ Basic Sciences Department, College of Engineering, University of Business and Technology, Jeddah, \\ Saudi Arabia \\ *E-mail: ahmad.shawqi@gmail.com
}

doi: $10.20964 / 2018.04 .15$

Received: 22 November 2017 / Accepted: 15 January 2018 / Published: 6 March 2018

\begin{abstract}
This study focuses on the electrodeposition of 2-nitrophenol, 3-nitrophenol, and 4-nitrophenol in either acidic, alkaline or neutral aqueous solutions. All the isomers have been electropolymerized using cyclic voltammetry $(\mathrm{CV})$. A notable feature in all $\mathrm{CV}$ measurements was that the insulating polymer films deposited on gold electrodes $\left(A=0.02 \mathrm{~cm}^{2}\right)$ from solutions were revealed by the rapid drop in current measured, when compared to the original CV scans. Generally, the anodic oxidation potential for 3-nitrophenol was slightly lower than that for 2-nitrophenol and 4-nitrophenol electropolymerized from solutions of similar $\mathrm{pH}$. Values of the molecular orbital energies of the HOMO and LUMO orbitals of the nitrophenol monomers in various ionization states were determined. Energy values were calculated and used to explain the electrochemistry of nitrophenol isomers. Electropolymerization of nitrophenol isomers was found to be most difficult in acid and easiest in basic medium. This was also confirmed by the calculated diffusion coefficients of the monmers. In conclusion, 3-nitrophenol showed the best electropolymerization performance, and 2-nitropehnol showed very poor coverage on the electrode surface.
\end{abstract}

Keywords: Modified Electrodes; Thin Film; Oxidation; Diffusion.

\section{FULL TEXT}

(C) 2018 The Authors. Published by ESG (www.electrochemsci.org). This article is an open access article distributed under the terms and conditions of the Creative Commons Attribution license (http://creativecommons.org/licenses/by/4.0/). 